\title{
A Panting Consciousness: Beckett, Breath, and Biocognitive Feedback
}

\section{Marco Bernini}

\section{BREATH AND CONSCIOUSNESS: A Co-DEPENDENT InTIMACY}

Booming Western interest in mindfulness and meditation has significantly mainstreamed breath and breathing practices. Mobile apps guiding breath-focused meditation are democratising, more or less carefully, earlier Buddhist intuitions of a tight, looping relation between body and mind, breath and mental states. Cognitive sciences too are starting to take the link between breathing and consciousness seriously. Breath is treated, for example, both as a symptom of stress disorders (such as hyperventilation in anxiety or OCD $)^{1}$ and a possible attenuating cure for distressing mental states. ${ }^{2}$ The therapeutic power of breathing is also key to the working of sensory deprivation technologies such as floatation tanks ${ }^{3}$ or sonic cradles. ${ }^{4}$

The cross-methodological benefits of looking at Buddhist practices, and at the relationship between breath and consciousness, for a better

M. Bernini $(\bowtie)$

Department of English Studies, University of Durham, Durham, UK

(C) The Author(s) 2021

D. Fuller et al. (eds.), The Life of Breath in Literature, Culture

and Medicine, Palgrave Studies in Literature, Science and Medicine, https://doi.org/10.1007/978-3-030-74443-4_21 
understanding of the human mind have been advocated by neurophenomenologists and philosophers of the cognitive sciences such as Francisco Varela, Evan Thompson, and Owen Flanagan. ${ }^{5}$ Within this intercultural scientific agenda, breath is considered as a way to access an 'open awareness ${ }^{6}$ of pre-reflective, minimal, foundational levels of consciousness and subjectivity. More than a century ago William James reflected on the intimacy of breath and consciousness by venturing the even more radical idea that our background feeling of a unified consciousness is actually materially anchored in, if not equivalent to, our breath. This is a mysterious claim; yet one that can today be illuminated by, and integrated with, contemporary scientific frameworks.

Whether technologically enhanced in artificial spaces or modulated in natural meditative environments, focussed breathing is therefore conducive to novel psychological states. Thanks to the regulation of breathing patterns, patterns in our thinking are not just affected, but revealed, together with their entanglement with respiration. Bodily proprioception and cognitive introspection thus converge in a mutual, looping modulation that discloses a dynamic relationship between biological and cognitive domains (or what this essay will describe it as 'biocognitive feedback'). ${ }^{7}$ What makes this reciprocal feedback possible is the structural intimacy and co-dependence of body and mind, in line with contemporary post-Cartesian cognitive sciences that see cognition as deeply embodied and shaped by actions, including the enactment of different breathing patterns. ${ }^{8}$

This essay investigates the co-dependent intimacy between breath and cognition as represented, explored, and complicated in the narrative work of Samuel Beckett. Some of Beckett's fictional environments, notably from the 1950s onwards, might indeed feel to his readers or audience like sensory deprivation tanks. Nothing there can be seen clearly, and therefore something or someone in the end appears or, as in What Where (1983), 'reappears'.9 Such works include, for example, The Unnamable (1953), where the narrating voice begins as a planet floating in a cosmic void (or so it pictures itself because 'how can one be sure in such a darkness?' ${ }^{10}$ while hallucinating presences from Beckett's imagistic universe; or Company (1980), which can also be experienced as a sustained solitary training in blinded flotation. Here a character is horizontally lying 'on his back in the dark', when this sensory indeterminacy is lit by projected images from the character's past. Together with emergent autobiographical visions, however, he also gradually attunes to minimal proprioceptive 
knowledge, and notably to the sound of his breath ('Apart from the voice and the faint sound of his breath there is no sound. None at least that he can hear. This he can tell by the faint sound of his breath'). In line with models of biocognitive regulatory feedback between breath and cognition, he simultaneously also accesses minimal states of consciousness ('in the dark in that dim mind'). ${ }^{11}$

Sensory deprivation is thus to Beckett's characters (and, vicariously, to his readers and audience) generative of new perceptual and attentional modes. This enhanced, regressive attention slowly makes them better acquainted with primary sensations as cognitive and physiological organisms. What they access, this essay will argue, is the restless biocognitive feedback activity between minds and bodies, including resonances or frictions between patterns of breathing and states of consciousness. In this proprioceptive-introspective new attentional mode, the relationship between breath and consciousness is revealed, in Beckett's work, as a complex, fraught intimacy. Beckett notoriously devoted an entire piece, albeit performatively brief, to the act of breathing (Breath, 1969). ${ }^{12}$ This work has received extensive critical attention, including a recent full-length monograph. ${ }^{13}$ Less explicit, more nested, incrementally distributed, and cross-medially explored references to breath and consciousness in Beckett's work have received comparatively little attention. This essay will therefore avoid an analysis of Beckett's most celebrated (but also more symbolic or metaphorical) tribute to breath, to investigate his subtler exploration of breath's intimacy with consciousness and cognition against models of their relation as formulated by classic and contemporary cognitive science.

\section{The 'I-Breathe': Agency, Time-Consciousness, AND Biocognitive Tempos}

Let us begin with William James' radical view of 'consciousness-as-breath' to evaluate how it can be set in dialogue with Beckett's modelling of biocognitive feedback. James' model requires gradual unpacking and speculative interpretation to introduce aspects of consciousness and breath that are key to understanding more contemporary models. In his Principles of Psychology (1890) James attempted multiple metaphorical descriptions to capture the nature, essence, and phenomenology of consciousness. The most famous of these sometimes conflicting metaphors is the idea of consciousness as a 'stream'. ${ }^{14}$ With this image 
James attacked previous conceptualisations of consciousness as a jointed sequence of discrete thoughts. This static and mechanical view did not account, James argued, for the unified, dynamic flowing of consciousness, because consciousness 'does not appear to itself chopped up in bits. [...] It is nothing jointed; it flows. A "river" or a "stream" are the metaphors by which it is most naturally described. In talking of it hereafter let us call it the stream of thought, of consciousness, or of subjective life'. ${ }^{15}$ The image of a stream helped James to highlight the lack of gaps in subjective experience, as well as to assign to consciousness an agency of its own ('it flows'); thus, accounting also for subjective experiences beyond our control (e.g., mind-wandering).

The impact of James' metaphor for psychology, and even more for literary studies, can hardly be overstated. What is less acknowledged is that, only a few years later, James grew deeply dissatisfied with this model. More specifically, and quite surprisingly for the putative father of the field of consciousness study, he felt that the very concept of consciousness needed to be eliminated. In his essay 'Does Consciousness Exist?' (1904), he begins with a lapidary eradication of the concept by stating that consciousness 'is the name of a nonentity, and has no right to a place among first principles. Those who still cling to it are clinging to a mere echo, the faint rumor left behind by the disappearing "soul" upon the air of philosophy'. ${ }^{16}$ What follows is a landmark example of James' new radical empiricist method, in which he interrogates the reasons behind the resilience of a concept defining such a diaphanous object of research. In doing so, however, and in spite of indulging in some analogical exemplifications, he refrains from devising new metaphors.

Metaphors such as the stream have previously been used by James 'to negotiate ethereal explanations for consciousness with bodily processes'. 17 This is actually what, according to embodied cognitive theories of figurative language, ${ }^{18}$ most metaphors do: in attempting to capture or to explore a more volatile or abstract phenomenon (the target of the metaphor; here, consciousness), metaphors project into it a more concrete domain (the source; here, the physical experience of a stream of water). In his later essay, however, James is keen to specify that he actually had 'mistrusted' consciousness as a target phenomenon or entity 'for the past twenty years', and that through consciousness metaphors he only 'tried to give [his students] its pragmatic equivalent in realities of experience'. Not anymore, however, because he claims that we should dismiss altogether the existence of consciousness as a distinct target, since '[i]t seems to me 
that the hour is ripe for it to be openly and universally discarded'. James is aware that dismissing consciousness might sound absurd, but he says it will be less so if the usual epistemic role attributed to consciousness is transferred to thoughts themselves: what we call consciousness, James says, is a 'function in experience that thoughts perform' and 'that function is knowing. "Consciousness" is supposed necessary to explain that things not only are, but get reported, are known'. ${ }^{19}$ For James, thoughts themselves can perform this epistemic function, by getting to know each other in reciprocal relations. The question is then what happens, in this rejection of the conceptual relevance of consciousness, to the phenomenological sense of a unified, sometimes agentively autonomous, flowing of conscious life that was captured by the image of the stream? Where are these qualities coming from? James' non-metaphorical answer is that they are actually generated by phenomenological biocognitive feedback coming from another unified, partly involuntary process: our breathing activity. The conclusion of his radical essay deserves full citation:

I am as confident as I am of anything that, in myself, the stream of thinking (which I recognize emphatically as a phenomenon) is only a careless name for what, when scrutinized, reveals itself to consist chiefly of the stream of my breathing. The 'I think' which Kant said must be able to accompany all my objects, is the 'I breathe' which actually does accompany them. There are other internal facts besides breathing (intracephalic muscular adjustments, etc., of which I have said a word in my larger Psychology), and these increase the assets of 'consciousness,' so far as the latter is subject to immediate perception; but breath, which was ever the original of 'spirit,' breath moving outwards, between the glottis and the nostrils, is, I am persuaded, the essence out of which philosophers have constructed the entity known to them as consciousness. That entity is fictitious, while thoughts in the concrete are fully real. ${ }^{20}$

It is important not to consider this conclusion as another metaphorical descriptor for consciousness. Here James is suggesting rather that the phenomenological qualities we attribute to consciousness are instead (not also) to be found in the process of breathing. The reason we carelessly conceptualise consciousness as a separate entity, James says, is that bodily states, and chiefly breathing, generate feedback into our qualitative experience of mental states. We then erroneously consider the latter as having properties that are instead projected (phenomenologically, not metaphorically) by the former. This means that if we look more carefully at our immediate perception of breathing, we should find qualities 
that we usually attribute to consciousness. This might seem far-fetched, but on closer scrutiny the two processes share a number of constitutive elements.

The first can be individuated in the particularly shifty agency of both breathing and consciousness. Breath, as well as consciousness, is a diaphanous process: a process we mostly live through, and which goes on in the background of our experience without us having to be in control of it, or being able fully to stop by sheer will. This agentive autonomy is also at the core of the felt escorting quality of consciousness, which accompanies our thoughts and mental states without us being able to control entirely its background patterns, or to shut it down apart from when falling asleep. For James, it seems that feedback from the semivoluntary agency of breathing feeds into conscious thinking, and informs its phenomenological properties. Related to this agentive autonomy, James' reconceptualisation of the Cartesian cogito as a misnomer for the 'I-Breathe' prompts us to look into the act of breathing as a possible contributor to the feeling of a unified temporal continuity of experience. If we turn to the phenomenology of temporality, or what phenomenologists call 'time-consciousness', ${ }^{21}$ we can consider whether its structuring components can be found in the breathing experience too.

Since Husserl's seminal analysis of human perception of time, phenomenologists have endorsed his view that the feeling of temporal flow in experience is rooted in each perception having a 'retentive' and 'protentive' aspect. Taking musical notes as an exemplification, Husserl suggested that the reason we perceive a unified stream of notes as a melody is that each impression of a note presents itself with a 'retention' of what just passed and a 'protention' of what is likely to follow. ${ }^{22}$ Timeconsciousness therefore feels continuous because of these two crucial phenomenological edges in each conscious perception. If we are to find in breathing the Ur-model of time-consciousness, retention and protention can be seen to have phenomenological foundational roots in the process of inspiration and expiration. Each retentive inhalation ends in a protentive horizon of expiration, and vice versa. The bodily breathing cycle is therefore ordered by a pendulum of retentive-protentive moments that might feed back into our feeling of a temporal continuity of consciousness.

Together with agency and temporality, a third element that breathing shares with what we think of as our consciousness is presenting different tempos. Abnormal patterns of breathing such as hyperventilation 
might resonate, for instance, with accelerated, hyper-reflexive patterns of thinking. ${ }^{23}$ In his radical eradication of consciousness, however, James would probably suggest that, even if biocognitive feedback between breath and thoughts (thoughts that are, for James, real) is occurring, it is only through our perception of an altered breathing that we perceive an analogous unified, altered tempo in our consciousness (the latter being, for James, the fictitious outcome of breathing feedback).

James' empiricist evaluation of the relationship between breath and consciousness ends in a full phenomenological overlapping of the two processes; or better, in subsuming phenomenological aspects of consciousness (agency, temporality, and tempos) into the enactive experience of breathing. For him, the intimate co-dependency turns out to be an identity. This does not rule out the importance of biocognitive feedback; if anything, it reinforces the phenomenological impact, but it makes biocognitive feedback asymmetrical and unidirectional. Its role in the 'I-Breathe' assigns to bodily respiration a phenomenological priority and the sole ontological validity. It is breath, not consciousness, whose agency, temporality, and tempos envelop our thoughts.

Beckett only had an indirect and cursory knowledge of William James. $^{24}$ And yet, James' equation of thinking with breath seems at first neatly to match Beckett's modelling of the biocognitive relationship between consciousness and breathing in relation to agency, temporality, and rhythmic tempos. Throughout his entire corpus, in fact, we find characters suffering the impossibility of agentively controlling and temporally stopping a consciousness that keeps going on with frantic tempos. As in James' model, often these qualities do not just resemble or mirror bodily patterns of breathing, but they seem experienced, in biocognitive synchronies, as bodily patterns. In Texts for Nothing (written 19501951), for instance, we have an unnamed character who is not just comparing, but synchronically equating thinking and breathing, 'so given am I to thinking with my breath'. ${ }^{25}$ By the same token, full breathlessness is at times synchronically experienced as a pleasant silencing of consciousness, for example by the protagonist of the short story The Calmative (written in 1946) who, in his 'distant refuge', feels finally at rest with his 'head bowed, weak, breathless, calm, free'. ${ }^{26}$ Another character in Texts for Nothing wishes his 'breath [to] fail better', to reach a state where the mind also will be silent ('to be silent'): a condition that will also shut down the epistemic function of knowing that we usually 
attribute to consciousness ('I'll be silent, I'll know I'm silence, no, in the silence you can't know'). ${ }^{27}$

Even by an external, 'heterophenomenological' perspective', ${ }^{28}$ the way Beckett's characters breathe is an embodied, material index indicative of the altered tempo of their mental struggles. In Not I (1972), for instance, a lit mouth in a darkened stage channels a cascade of thoughts through breathing patterns at the limit of human performative possibilities. The hyperventilating required of the actress marks patterns of hyper-reflexive anxiety at the level of the contents. In a letter to the director Alan Schneider about this play, Beckett wrote how he saw 'her speech [as] a purely buccal phenomenon without mental control and understanding'. ${ }^{29}$ Here Beckett seems to be touching upon the sense of a lack of agency in consciousness, which he links, as James would have it, to a lack of control of breathing tempo: 'I hear it breathless, urgent, feverish, rhythmic, panting along, without undue concern with intelligibility. Addressed less to the understanding than to the nerves of the audience which should in a sense share her bewilderment'. ${ }^{30}$ In a biocognitive synchronic view of consciousness-as-breath, the panting respiration of Not $I$ is the only unifying process that grants cohesion to otherwise centripetal, disjointed thoughts. It is a panting breath, not a streaming consciousness, which pushes thoughts temporally forward, in steady acceleration. There is no separate, reflective consciousness taking these thoughts as epistemic objects, and Beckett wanted the enactive experience of a panting breathing to be the primary, material index of frantic states of mind.

Beckett had modelled a similar panting consciousness a few years before in How It Is (1961), this time in the novelistic medium. Assuming that literary narratives require readers' silent subvocalising of the text, ${ }^{31}$ in How It Is readers are forced to a more direct, sensorimotor enactive experience of consciousness as bodily articulated. In this highly experimental novel that has only the shadow skeleton of a standard plot (in Beckett's words, "A "man" is lying panting in the mud and dark murmuring his "life" as he hears it obscurely uttered by a voice inside him'), ${ }^{32}$ the primary meaning seems to be found in the very experience of the articulatory efforts in subvocalising these panting words and/as thoughts. When Robert Pinget received a copy of the original French version of the text (Comment C'est) in 1960, he reported how this subvocalising effort was testing the limit of the reader, and daunting any prospect of translation. In his account of a conversation he had with Beckett he explains how he 
told him 'that for him [the third] is the weakest part. I agree, but one breathes more easily in it. The gasping in the first two parts is unbearable'. ${ }^{33}$ In 1960 Patrick Magee also manifested worries about how to openly vocalise the text in a public performance. The only help Beckett thought he could offer was to supplement the lack of punctuation in the novel by marking rhythms, while suggesting, via his editor Barney Rosset, that '[a]ll he can do is gasp it out very short of breath, into a microphone if possible, and hope for the best. I have marked the rhythms on his copy' ${ }^{34}$ The rhythmic percussion of breathed words, in fact, has no diacritical signals of rest, but only typographical spaces between blocks. These are arguably the moments when, as we are told, 'the panting stops $^{35}$ and therefore markers of longer inhaling gaps between panting gasps of thoughts. It seems that, through formal manipulations of the narrative medium, Beckett has managed to force readers, performers, and translators to a material experience of consciousness as a panting breath close to the synchronic model promoted by James. If we look at the contents that are frantically breathed into the characters, however, this model seems to be only partly explanatory of Beckett's exploration of the link between consciousness and breath.

Similar to Not $I$, in fact, the contents of these thoughts are flashes from the character's life that are pushed forward with an agency that the character disowns. More specifically, these thoughts, we are told, are coming from above: from a voice 'once without quaqua on all sides then within me when the panting stops'. The novel therefore discloses a vertical cognitive architecture of levels that complicates the idea that what we are panting through is a single, biocognitively synchronic Jamesian layer of a breathing consciousness. Early commentators have already stressed how the mud can be considered as an extended metaphor transforming consciousness into a place or space traversed by the character; and how its geography seems located at the bottom of unspecified geological layers. Ruby Cohn, for instance, claims that ' $[\mathrm{m}] \mathrm{ud}$ is an inspired metaphor for consciousness-warm and traversable. Above the novel's mud is life in the light, with its dreams, memories, and fantasies, but the mud itself is a performative medium: curtains can open within it, as in the theater; images and scenes can vanish through cinematic blackouts.' 36 I endorse Cohn's interpretation, which in the framework we are advancing can be reconceptualised as follows: the mud does not just stand for consciousness, but is a modelling solution that allowed Beckett to introduce an enactive performance of consciousness as biocognitively linked to breath. 
However, even if the mud is the viscous material that gives panting the right phenomenological feeling of 'pushing against' some agentive imperative, it seems it is not the mud itself that generates the retentiveprotentive movement. The imperative of panting forward comes from some other level, and the mud can rather be said to allow a performance of an asynchrony between the level of panting and the agentive source of the panting driving tempo. It seems therefore that James' model of consciousness-as-breath, while it has a lot to offer to Beckett's fictional modelling of the biocognitive feedback between breath and consciousness, cannot account in full for the asynchronous divorce in their primary and primitive intimacy. We need to find models accounting for different levels of interaction between breath and consciousness, for models spatialising, as Beckett does, different kinds of consciousness, and set them in biocognitive relations with breath.

\section{BREATHING MEDiACY: KNOWING, EXPERIENCING, WitNESSING}

\section{Knowing, Experiencing, Witnessing}

Such models can be found in contemporary cognitive sciences, including Buddhist-inspired cognitive scientific frameworks. Instead of simplifying or dissolving the problem of consciousness into a single level having unidirectional biocognitive feedback (as in the 'consciousness-as-breath' model in James), contemporary cognitive sciences promote a multilevel view of different kinds of consciousness. Multilevel models of consciousness have taken up different names in different thinkers or approaches. All of them share, however, a distinction between more bodily, temporally local, pre-reflective stages or states, on which higher stages or states are building to produce reflective, autobiographical, temporally extended feelings of continuity for the organism. Once this architecture is established, biocognitive feedback between lower and higher levels may occur.

The primary, pre-reflective type of consciousness has been variously defined as a "core'37 or 'minimal'38 stage and state. Here, the organism has only a 'thin' or 'experiential' 39 sense of being a bodily self, moving in time. On top of this eminently bodily, phenomenologically thin state, an 'extended' level hosting higher states of consciousness arises: this is the level of thoughts, episodic memories, mental imagery, autobiographical narratives, leading to the more conceptual continuity of an 'autobiographical self ${ }^{40}$ spanning larger portions of time. Core or thin 
levels are, in this account, necessary for more extended or autobiographical levels of consciousness to emerge. Usually, we are neither aware of this nested architecture nor of biocognitive feedback between levels.

What Buddhist-inspired cognitive models of consciousness add to this picture is the possibility of training ourselves in cultivating subtler degrees of awareness of, and an attentional navigation across, these levels. As Thompson points out, however, 'subtler or deeper aspects of consciousness aren't apparent to the ordinary untrained mind; they take a high degree of meditative awareness to discern'. ${ }^{41}$ By training our attention to breathing we can progress, or regress, within this continuum of awareness towards a subtler sense of the nested structure of conscious levels as well as of their biocognitive intermodulation and potentially asynchronous patterns. By attuning to breathing, we can magnetise our attention away from higher levels of thoughts, images, and concepts (that we usually feel as the only constitutive elements of our life and self) towards more primordial feelings of core aliveness. We can move, in short, from extended levels of consciousness down to core bodily states of primary awareness, and this can potentially send slowing, regulatory feedback (as it were) from the bottom up.

This multilevel model of consciousness seems more capable of accounting for asynchronous biocognitive feedback within Beckett's characters. It gives a hermeneutic, spatial structure to map their attempts to move away from higher forms of consciousness towards minimal bodily feelings. Since Beckett's first novelistic efforts, in fact, we find characters not only thinking with their breath, but trying to alter thinking by modulating breathing patterns. In Dream of Fair to Middling Women (written in 1932, published posthumously in 1992), we see the protagonist, Belacqua, training himself to regress into a meditative darkness, away from his restless thoughts. In what reads like a wonderful slapstick rendition of a self-taught meditational practice, we assist at his active attempts to manipulate biocognitive feedback between bodily and mental states, beginning with breathing patterns:

He trained his little brain to hold its breath, he made covenants of all kinds with his senses, he forced the lids of the little brain down against the flaring bric-à-brac, in every imaginable way he flogged on his coenaesthesis to enwomb him, to exclude the bric-à-brac and expunge his consciousness. $\mathrm{He}$ learned how with his knuckles to press torrents of violet from his eyeballs, he lay in his skin on his belly on the bed, his face crushed grossly into 
the pillow, pressing down towards the bearings of the earth with all the pitiful little weight of his inertia, for hours and hours, until he would begin and all things to descend, ponderously and softly to lapse downwards through darkness, he and the bed and the room and the world. All for nothing. He was grotesque, wanting to 'troglodyse' himself, worse than grotesque. It was impossible to switch off the inward glare, wilfully to suppress the bureaucratic mind. It was stupid to imagine that he could be organised as Limbo and wombtomb, worse than stupid. ${ }^{42}$

It would be possible to interpret the initial reference to the brain's breath or lids as metaphorical, 'psycho-analogical' ${ }^{43}$ projections of bodily actions (breathing, closing eyelids) targeting the more abstract domain of conscious thoughts. Given the following extensive description of actual physical manoeuvres Belacqua undertakes to silence his higher cognitive apparatus, however, it is better to understand those references as syncretic, condensed descriptions of biocognitive practices of regulation he concretely operates to move downward levels of consciousness. Belacqua slows the pace of his brain (a noun that is a synecdoche for conscious thinking) by actually slowing down his physical breathing process. This non-metaphorical interpretation of the brain's breath is reinforced by the discovery, a few lines later, that the closing of the brain's 'lids' is also a biocognitive feedback he tries to generate by physically closing his eyelids, as in sensory deprivation practices.

Belacqua therefore attempts biocognitive covenants between mind and bodily processes, trying to affect the former through the latter. He does so in order to move away from the higher, extended level of consciousness (the kind of consciousness he wants to 'expunge') down to a more primitive, core (in his imagery, 'troglodyte') level of cognition. This meditative regression, however, is doomed to fail because of an asynchronous resistance of higher consciousness to biocognitive, upward regulation coming from bodily senses, breathing patterns included. It is rather the extended, 'bureaucratic mind' which agentively wants the organism to pant synchronically forward, in accordance with its frantic tempos. If Belacqua is not attaining any rest in his core level of consciousness we, as readers, are nonetheless getting a sense of the multilevel structure of his life as a living human organism; notably, of the asynchronous biocognitive tension between a physical breath that wants to slow down the mind, and an extended consciousness that wants the body to move in tandem panting along. 
The transition that Belacqua would like to make, through biocognitive breathing modulations, is therefore one from a higher, agentive, and autobiographically charged level of consciousness to a lower, core level of minimal consciousness. This transition can be understood, in contemporary phenomenology of mind, as a downward movement from knowing to experience. If extended consciousness is the realm of knowledge (e.g., beliefs, autobiographical information, conceptual identities, and wilful control), the core level hosts what Dan Zahavi has called an 'experiential self', which is endowed only with a 'first-personal presence of experience' ${ }^{44}$ Without or before having to know anything about the content of experience, the experiential self we found in the core level does not require a diachronic unity threaded with autobiographical narratives or conceptual information about the world. It only needs an 'experiential continuity': ${ }^{45}$ a minimal givenness and presence whose thin temporality is guaranteed by strictly localised phenomenological retentions and protentions offered to his 'interoceptive sensitivity' ${ }^{46}$ by bodily processes such as breathing patterns. For the experiential self, as Thompson puts it, the act of breathing is among the 'self-specifying processes [which] support an interoceptive sense of self-a feeling from within of one's body as that which inhabits the sensorimotor perspective from which one perceives and acts'. ${ }^{47}$

This experiential level of subjectivity of our core consciousness is therefore the primordial, yet always active ground of our cognitive life. Once we develop from experiential to epistemic levels of cognition, however, it mostly becomes hidden below the noisy, verbal, conceptual, imagistic surface of our extended consciousness. Given the intimate role of breath in shaping our core consciousness, as Thompson notes, if we want to regress back to our cognitive foundation 'it's therefore no surprise that so many types of meditation begin with focused attention to the sensation of the breath as a way of centering our awareness on our embodied being in the present moment'. ${ }^{48}$ Moving away from a knowing mode towards an experiential stance, however, is not just difficult for Belacqua, but even for proper meditators. This is due to the asynchronous tensions between the extended level of conscious verbal thinking, beliefs, judgments, or mental imagery and the core, interoceptive level of bodily processes. Focused breathing can nonetheless be revealing of such tensions, as Varela, Thompson, and Rosch explain: 
Breathing is one of the most simple, basic, ever-present bodily activities. Yet beginning meditators are generally astonished at how difficult it is to be mindful of even so uncomplex an object. Meditators discover that mind and body are not coordinated. The body is sitting, but the mind is seized constantly by thoughts, feelings, inner conversations, daydreams, fantasies, sleepiness, opinions, theories, judgments about thoughts and feelings, judgments about judgments - a never ending torrent of disconnected mental events that the meditators do not even realize are occurring except at those brief instants when they remember what they are doing. Even when they attempt to return to their object of mindfulness, the breath, they may discover that they are only thinking about the breath rather than being mindful of the breath. ${ }^{49}$

Thinking and breathing, core and extended consciousness, are revealed to meditators as lacking coordination. Meditators, like Belacqua, attempt to attune to their core level of consciousness by expunging the seizing, agentive tempos of thoughts, opinions, judgments, theories, and much more. This proves difficult, and to Belacqua impossible, because extended consciousness keeps pulling the organism into higher levels of cognition. The organism therefore becomes the battlefield of biocognitive feedback loops coming from both levels, each trying to modulate the other towards its pace, patterns, and state.

This way, meditators become aware of how the original, ontogenetically primordial, co-dependent intimacy of breath and consciousness in core states has evolved into a divorced tension that resists synchronic convergence and remodulation. Extended and core states develop a different agency, temporality and tempos set in asynchronous negotiations. Core consciousness, on the one hand, still presents the pulsing semi-autonomous agency of an organism living in a thin present. The part of the organism in this state moves forwards at the slower pace of minimal retentions and protentions, rooted in bodily processes such as inspiration and expiration. Extended consciousness, instead, has a much more ambitious, temporally thick, and frantic kinetics. It restlessly casts narratives, beliefs, judgments, and memories retaining the distant past that it projects into the future.

These two levels coexist in the human organism, and this is why meditators can attempt to shift from a state of extended knowledge to a state of experiential mindfulness within themselves. Beckett, however, after having portrayed self-taught meditators such as Belacqua or Murphy (1938; who ties himself to a rocking chair to regress into liminal 
states of consciousness $)^{50}$ decides to explore the asynchronous biocognitive tensions between knowledge and experiential levels by separating them into distinct agents and agentive positions. Company, for example, pictures a character lying on his back in the dark, when a mysterious voice begins telling him 'of a past. With occasional allusion to a present and more rarely to a future as for example. You will end as you now are'. Within the multilevel model of consciousness, the voice can be considered as coming from the extended level, pulling the one in the dark out of his core state by the downward channelling of autobiographical memories. The one in the dark is instead located in a lower, core state ('Your mind never active at any time is now even less than ever so. This is the type of assertion he does not question'), ${ }^{51}$ whose temporality is thinner than any narrative, only interoceptively grounded in the retentive and protentive emissions of his breath.

The short novella seems to spatialise extended and core consciousness into higher and lower positions, each with its distinct agency, temporality, and tempos. If the voice at the higher level is relentlessly pushing broader narrative arches down into the organism, the one in the dark seems mindfully attuned to the semi-voluntary agency of his breath, infusing his experience just with a presentified slowed tempo. The plot of the novella can be summed up as the story of biocognitive feedback, looping downwards and upwards, without a synchronic resolution. Other texts in Beckett's work similarly model the interplay, interpenetration, and fraught intimacy between extended and core levels as a biocognitive struggle of distinct agentive positions within the same organism. That Time (1976), for instance, equally stages three voices coming to an old man, listening to them with his eyes open and 'His breath audible, slow and regular'. The slow pace of the breath of the character mirrors his minimal responsiveness to the voices that, once again, are forcing upon him memories from his past, 'back and forth without any break in general flow'. ${ }^{52}$ This time we are not given any access to the character's mind, and the slowed tempo of his breath is the only index of the asynchronous rhythm of his core aliveness compared to the incessant pace of his voiced memories.

Both texts therefore model the assault that extended levels of consciousness are launching towards minimal stages of the organism, and the resistance opposed by the latter. We assist at biocognitive conflicts between knowledge and memories that are, through voices, agentively breathed into the characters (with obvious biblical echoes); and listening 
organisms that are trying to stay attuned to the different, more primordial breathing patterns of core states. These biocognitive downwards and upwards negotiations can be conceptualised as two different kinds of breathing mediacies. ${ }^{53}$ On the higher position, we have the faster, agentive emissions of the breathing voices of memory and knowledge, which attempt to mediate lower organisms up into extended levels of cognition. On the lower level, we have organisms attempting to anchor, as meditators do, to breath as a mediating interoceptive signal to silence thoughts, memories, judgments, beliefs, and so on.

It could be argued that the former kind of informational breath is more of a metaphoric kind of mediacy compared to the physical breath, which mediates access to lower core states. James' idea that our extended consciousness feels the way it does because of its roots in the retentions and protentions of breathing, however, can explain why Beckett decided to render even higher levels of cognition as having breathing patterns. There is another reason, though, that can cast further light on why Beckett opted to model the mediacy of breathing thoughts as voices. Elsewhere, I have argued that this may be due to Beckett's modelling the dynamic of inner speech, and its role in verbalising knowledge into a pre-reflective, lower state of the organism. ${ }^{54}$ As cognitive psychological research on inner speech shows, ${ }^{55}$ our inner conversations situate us both in the position of the producer and the receiver of knowledge about ourselves and about the world. As a producer, we are located in the extended level that takes agentive charge of the information to be channelled. As a receiver, or, as Beckett's fictional models define it, a listener, we are more experientially hearing knowledge about ourselves and about the world. We become an experiential object of conversation.

The dynamic structure of inner speech is therefore isomorphic to respiration. In a looping circle, we listen as we inspire; and we internally talk as we expire. The inhaling moment is thus equivalent to the breathing mediacy through which an autobiographical life is channelled into a lower organism. This core organism would feel, as a meditator does, as if thoughts, images, beliefs, and judgments have been pushed on him; as a listener who then has to exhale some lesson imparted to him. This is the kind of phenomenological report we read in The Unnamable, in which the narrator is constantly disowning the contents of his narrative by explaining how he is only exhaling a lesson ('They gave me courses on love, on intelligence, most precious, most precious. They also taught me to count, and even to reason') that has been breathed into him ('They 
blow me up with their voices, like a balloon, and even as I collapse it's them I hear'). 56

In Beckett's work across different media, we therefore assist, and vicariously undertake, what it is like to be an experiential core self asynchronically battling against the agency of thoughts, beliefs, judgment, and images that core selves are forced to inhale and then exhale at accelerated tempos. They discharge the contents of an extended consciousness ('a pensum to discharge') (7) $^{57}$ that commands them to pant forward, away from more primitive and primary patterns of breathing and consciousness. As James explains in his Talks to Teachers (1899), sometimes consciousness discharges in outer behaviours: 'there is no sort of consciousness whatever, be it sensation, feeling, or idea, which does not directly and of itself tend to discharge into some motor effect. [...] It may be only an alteration of the heart-beats or breathing' ${ }^{58}$ This seems to be the kind of motoric discharge of extended states in works like Not I, How It Is, and The Unnamable. If extended and core consciousness have different agency, temporality, and tempos (hence some of the limits of James' model), the former might tyrannously force its patterns onto the latter, which then becomes a state of non-agentive exhalation of inhaled knowledge (as in Not I, 'just the birth cry to get her going ... breathing ... then no more till this'; ${ }^{59}$ or in Ceiling, 'Dull with breath. Endless breath. Endless ending breath.'). ${ }^{60}$ Accordingly, the breathing voices in Beckett's work are perceived by the experiential characters as masters, guardians, judges, or tyrants ('my college of tyrants') ${ }^{61}$ with asymmetric knowledge compared to the experiential subjects.

Breath is therefore key to Beckett's exploration of asynchronous biocognitive feedback between levels of knowledge and levels of experience in conscious human organisms. Different agency, temporality, and tempos in different levels of consciousness present different breathing patterns in his work. Patterns of breath are either an index of hectically discharged knowledge, or a core, pulsing signal of experiential resistance to that knowledge by the organism. Intruding knowledge or experiential mindfulness, however, are not the only options for focussed breathing meditation, nor do they seem to be for Beckett's characters. A third, ultimate attentional shift awaits the skilful meditator: an access to a mode of consciousness behind and beyond extended and experiential states. This further state is what Thompson describes as 'open awareness', which usually begins with a focus on breathing and then 'takes the form of witnessing thoughts, emotions, and sensations as they arise from moment 
to moment, and observing their qualities' ${ }^{62}$ When a meditator reaches this stage, she is neither in the extended nor in the core state, but detaches from both to watch unjudgmentally their biocognitive feedback from an outside stance.

While in this state, the organism is aware of both levels and of their reciprocal negotiations 'without identifying with them or with the self that appears in them.' ${ }^{63}$ Building on Vipassanā terminology, Thompson defines open awareness accordingly as 'non-reactive', 'nonclinging', or 'non-grasping'. A state where one simply 'observes or witnesses the coming and going of sensory and mental events without getting caught up in cognitive and emotional reactions'. ${ }^{64}$ Reworking the same Vipassanā tradition in analytic philosophical terms, Miri Albahari calls this deeper level of awareness 'witness-consciousness': a further level which is 'the raw registration of any experience'. ${ }^{65}$ Physiological breathing can therefore initiate the transition from knowledge to experience, and then itself become part of the broader, subjectless field of experience of witness-consciousness. Here the organism steps outside biocognitive synchronies and asynchronies: to some extent it steps outside chronological time altogether, watching the clashing of downwards and upwards feedback as one might watch rainstorms dampening the earth from a cosmological perspective.

The stupefied, unjudgmental, non-clinging features of witnessconsciousness seem to capture some of the unique qualities of Beckett's fictional organisms when they are not discharging thoughts or interoceptively attuned to minimal states. At the beginning of The Unnamable, we find the protagonist unjudgmentally noticing the appearance of two other protagonists from Beckett's previous novels: 'Malone is there. Of his mortal liveliness little trace remains. He passes before me at doubtless regular intervals, unless it is I who pass before him [...]. Perhaps it is Molloy, wearing Malone's hat. But it is more reasonable to suppose it is Malone, wearing his own hat. Oh look, there is the first thing, Malone's hat. ${ }^{\prime 66}$ This non-reactive observation of what resemble hallucinatory perceptions is close to Thompson's report of his own attaining of open awareness, where he describes how he 'slipped into a state where for some time I watched a parade of unfamiliar faces while I remained aware of the subtle feeling of the air entering and exiting my nostrils [...]. The faces seemed imaginary—creations of my mind-but also perceptual'. ${ }^{67}$ Here Thompson is highlighting how he experienced both mental images and bodily feelings without clinging to them. 
This kind of witnessing distance can be found in several moments within Beckett's fictional minds. In one of the Texts for Nothing, the narrating stance of the character seems remote both from extended and core levels of consciousness, even if he is still trying to intervene when 'I say to the body. Up with you now, and I can feel it struggling [...]. I say to the head. Leave it alone, stay quiet, it stops breathing, then pants on worse than ever' ${ }^{68}$ In spite of still caring for how bodily breath and breathing thoughts modulate each other, the character seems positioned outside their interaction. More blissful moments of witnessing detachment can be found in Malone Dies (1951), whose narrating protagonist feels he has trained himself to move beyond any attachment to his bodily and mental states: 'All my senses are trained full on me, me. Dark and silent and stale, I am no prey for them. I am far from the sound of blood and breath, immured' ${ }^{69}$ What makes Malone's non-reactive distance a captivating reading experience is precisely his non-clinging curiosity about the interplay between his old body and his dimming consciousness: 'My body does not yet make up his mind. But I fancy it weighs heavier on the bed, flattens and spreads. My breath, when it comes back, fills the room with its din, though my chest moves no more than a sleeping child's. I open my eyes and gaze unblinkingly and long at the night sky. So a tiny tot I gaped, first at the novelties, then at the antiquities'. ${ }^{70}$

More often than not, however, Beckett's characters are unable to attain or fully rest in such open awareness. It is rather the audience or readers who are positioned as witnesses of the incessant, sometimes cruel biocognitive mediacies between extended and core levels within the organism. Like Buster Keaton in Beckett's Film (1965), we are vicariously suffering the impossibility of finding an 'angle of immunity'71 to shelter ourselves from the breathing patterns of chasing guardians, masters, tormentors. As a result, we are panting along within Beckett's sensory-deprived storyworlds, which nonetheless turn into meditational technologies for training our attention to the intimate modulation between breathing and consciousness.

\section{CONCLUSION}

More could be said about Beckett's further analogical pairing between breathing and writing (see, e.g., Malone's non-agentive writing where 'the air that breathes through my pages turns them without my knowing', 72 or Texts for Nothing, with 'breathing in and out, with words like 
smoke' $)^{73}$ or about the guilt of breathing fictional creatures into life (since 'it is enough to breathe to qualify for asphyxiation'). ${ }^{74}$ The aim of this essay was to show, through the interpretive potential of cognitive scientific models, how Beckett's exploration of the co-dependent intimacy of breath and consciousness links to key contemporary problems in consciousness studies, notably in relation to new enactive accounts of biocognitive feedback between higher and lower levels of cognition. In broaching such a vast topic, interdisciplinarily, and in such a complex author, however, it is impossible not to feel as Beckett did when discussing with George Duthuit the relationship between art and subjectivity: 'All this is literary, over-simplified, but we breathe as best we can'. ${ }^{75}$

\section{Notes}

1. See, e.g., J. N. Han et al., 'Influence of Breathing Therapy on Complaints, Anxiety and Breathing Pattern in Patients with Hyperventilation Syndrome and Anxiety Disorders', Journal of Psychosomatic Research 41/5 (1996), 481-93; Antonio E. Nardi et al., 'Panic Disorder and Control of Breathing', Respiratory Physiology \& Neurobiology 167/1 (2009), 133-43; Luiz Dratcu, 'Panic, Hyperventilation and Perpetuation of Anxiety', Progress in Neuro-Psychopharmacology and Biological Psychiatry 24/7 (2000), 1069-89.

2. See, e.g., Michael E. Clark and Richard Hirschman, 'Effects of Paced Respiration on Anxiety Reduction in a Clinical Population', Biofeedback and Self-Regulation 15/3 (1990), 273-84; Ravinder Jerath et al., 'SelfRegulation of Breathing as a Primary Treatment for Anxiety', Applied Psychophysiology and Biofeedback 40/2 (2015), 107-15.

3. Jared R. Lindahl et al., 'A Phenomenology of Meditation-Induced Light Experiences: Traditional Buddhist and Neurobiological Perspectives', Frontiers in Psychology 4 (2014), 973.

4. Sonic Cradles are technologically enhanced environments for meditation, where in a chamber of complete darkness users can shape soundscapes by using their respiration. See Jay Vidyarthi et al., 'Sonic Cradle: Designing for an Immersive Experience of Meditation by Connecting Respiration to Music', Proceedings of the Designing Interactive Systems Conference (2012), 408-17.

5. See Francisco J. Varela, Evan Thompson, and Eleanor Rosch, The Embodied Mind: Cognitive Science and Human Experience (Cambridge, MA: MIT Press, 1993); Evan Thompson, Waking, Dreaming, Being: Self and Consciousness in Neuroscience, Meditation, and Philosophy (New York: 
Columbia University Press, 2015); Owen Flanagan, The Bodhisattva's Brain: Buddhism Naturalized (Cambridge, MA: MIT Press, 2011).

6. Thompson, Waking, Dreaming, Being, xxxiii.

7. I borrow from Mario Martinez the term 'biocognitive', which he uses to define the interaction between bodily, mental states, and actions, such as the possibility of breathing patterns affecting mental states, and vice versa. See Mario E. Martinez, 'The Process of Knowing: A Biocognitive Epistemology', The Journal of Mind and Behavior (2001), 407-26. Biocognitive feedback should be distinguished from 'biofeedback', which refers instead to feedback artificially obtained by linking the body to external technologies such as respiration in sonic cradles or the enhanced monitoring of heartbeats; see Clark and Hirschman, 'Effects of Paced Respiration'.

8. For a critical survey see Mark Rowlands, The New Science of Mind: From Extended to Embodied Phenomenology (Cambridge, MA: MIT Press, 2010).

9. Krapp's Last Tape and Other Short Plays, preface by S. E. Gontarski (London: Faber, 2009), 149-60.

10. Three Novels: Molloy, Malone Dies, The Unnamable, ed. by Stanley Gontarski (New York: Groove Press, 2009), 286.

11. Company, Ill Seen Ill Said, Worstward Ho, Stirring Still, ed. by Dirk Van Hulle (London: Faber, 2009), 3-4.

12. Krapp's Last Tape and Other Short Plays, 77-79.

13. Sozita Goudouna, Beckett's Breath: Anti-Theatricality and the Visual Arts (Edinburgh: Edinburgh University Press, 2018).

14. On James and mind metaphors see Jill M. Kress, 'Contesting Metaphors and the Discourse of Consciousness in William James', Journal of the History of Ideas, 61/2 (2000): 263-83.

15. The Principles of Psychology, Vol. I (New York: Dover, [1890] 2009), 239.

16. Essays in Radical Empiricism (Whithorn: Anodos Books, [1912] 2019), 5.

17. Kress, 'Contesting Metaphors', 264.

18. For embodied theories of metaphor and figurative language see George Lakoff and Mark Johnson, Metaphors We Live By (Chicago: University of Chicago Press, 1980); Raymond Gibbs, Interpreting Figurative Meaning (New York: Cambridge University Press, 2012).

19. Essays in Radical Empiricism, 5.

20. Essays in Radical Empiricism, 15-16.

21. See Shaun Gallagher and Dan Zahavi, The Phenomenological Mind (New York: Routledge, 2008), 83-90.

22. See Gallagher and Zahavi, The Phenomenological Mind, 84 .

23. On the phenomenology of hyper-reflexive states and their relation to consciousness and self see Dan Zahavi, Subjectivity and Selfhood: Investigating the First-Person Perspective (Cambridge, MA: MIT Press, 2005), 133-38. 
24. Beckett had a mediated access to William James while reading, in his formative years, Robert Woodworth's Contemporary Schools of Psychology (1931); see Rubin Rabinovitz, 'Beckett and Psychology,' Journal of Beckett Studies 11/12 (1989), 65-77.

25. Texts for Nothing and Other Shorter Proses 1950-1956, ed. by Mark Nixon (London: Faber, 2010), 30.

26. The Expelled, The Calmative, The End with First Love, ed. by Christopher Ricks (London: Faber, 2009), 20 (emphasis added).

27. Texts for Nothing, 34.

28. 'Heterophenomenology' is how Daniel Dennett describes the study of consciousness operated from the observation of outer behaviour whereby which we can infer phenomenological inner states. See Daniel Dennett, Consciousness Explained (London: Penguin, 1991).

29. The Letters of Samuel Beckett: Volume 4, 1966-1989, ed. by Martha Dow Fehsenfeld, Lois More Overbeck et al. (Cambridge: Cambridge University Press, 2016), 311.

30. Letters 4, 311 (emphasis added).

31. See, e.g., D. Reisberg, 'Subvocalization and Auditory Imagery: Interactions Between the Inner Ear and Inner Voice', Auditory Imagery (2014), 107-32. For an empirical study of inner speech, reading, and literary narratives see Ben Alderson-Day et al., 'Uncharted Features and Dynamics of Reading: Voices, Characters, and Crossing of Experiences', Consciousness and Cognition 49 (2017), 98-109.

32. The Letters of Samuel Beckett: Volume 3, 1957-65, ed. by Martha Dow Fehsenfeld et al. (Cambridge: Cambridge University Press, 2014), 326.

33. Letters 3, 352.

34. Letters 3, 327.

35. How It Is, ed. by Édouard Magessa O'Reilly (London: Faber, 2009), 3.

36. Ruby Cohn, A Beckett Canon (Ann Arbor: University of Michigan Press, 2005), 256.

37. See Antonio Damasio, Self Comes to Mind: Constructing the Conscious Brain (London: Heinemann, 2010).

38. See Shaun Gallagher, 'Philosophical Conceptions of the Self: Implications for Cognitive Science', Trends in Cognitive Sciences 4/1 (2000), 14-21.

39. The idea of a 'thin' or 'experiential' self is formulated by Dan Zahavi in 'The Experiential Self: Objections and Clarifications', in Self, No Self?: Perspectives from Analytical, Phenomenological, and Indian Traditions, ed. by Mark Siderits et al. (Oxford: Oxford University Press, 2011), 56-78. See also Dan Zahavi, 'Thin, Thinner, Thinnest: Defining the Minimal Self', in Embodiment, Enaction, and Culture: Investigating the Constitution of the Shared World, ed. by Christoph Durt et al. (Cambridge, MA: MIT Press, 2017), 193-99. 
40. The multilevel distinction between 'core' and 'extended consciousness' is paired by Damasio with a 'core' and 'autobiographical self', respectively, in Damasio, Self Comes to Mind. For a more recent cognitive scientific account of the autobiographical self see Mark Rowlands, Memory and the Self: Phenomenology, Science and Autobiography (New York: Oxford University Press, 2007).

41. Thompson, Waking, Dreaming, Being, 7.

42. Dream of Fair to Middling Women, ed. by Eoin O'Brien and Edith Fournier (New York: Arcade, 1992), 123 (emphasis added).

43. The term 'psycho-analogies' has been invented by Dorrit Cohn to define analogical images that the narrator or the character use to communicate mental states, especially when these are pre-verbal or opaque. See Dorrit Cohn, Transparent Minds: Narrative Modes for Presenting Consciousness in Fiction (Princeton: Princeton University Press, 1978).

44. Zahavi, 'The Experiential Self', 59.

45. Zahavi, 'The Experiential Self', 75.

46. Anil Seth, 'Interoceptive Inference, Emotion, and the Embodied Self', Trends in Cognitive Sciences 17/11 (2013), 565.

47. Thompson, Waking, Dreaming, Being, 336.

48. Thompson, Waking, Dreaming, Being, 336.

49. Varela et al., The Embodied Mind, 25.

50. Murphy, ed. by J. C. C. Mays (London: Faber, 2009).

51. Company, 4.

52. Krapp's Last Tape and Other Short Plays, 99.

53. The concept of 'mediacy' in narrative theory defines how the access to a story and a storyworld is mediated (by a narrator; a character; an empty, inorganic, or cosmological perspective, and so on). See Monika Fludernik, 'Mediacy, Mediation, Focalization: The Squaring of Terminological Circles', in Postclassical Narratology: Approaches and Analyses, ed. by Jan Alber and Monika Fludernik (Columbus: Ohio State University Press, 2010), 105-33. The ontological act through which a character is breathed into life through the mediating function of a narrator can be compared with the mediating function of memories through which an organism is breathed into autobiographical consciousness; see Marco Bernini, Beckett and the Cognitive Method: Mind, Models, and Exploratory Narratives (New York: Oxford University Press, 2021).

54. Bernini, Beckett and the Cognitive Method, Chapter 2 (45-84).

55. See Ben Alderson-Day and Charles Fernyhough, 'Inner Speech: Development, Cognitive Functions, Phenomenology, and Neurobiology', Psychological Bulletin 141/5 (2015), 931.

56. Three Novels, 292, 319.

57. Three Novels, 304. 
58. Talks to Teachers on Psychology (1899) (New York: Henry Holt, 1916), 170.

59. Krapp's Last Tape and Other Short Plays, 90.

60. Collected in Company, Ill Seen Ill Said, Worstward Ho, Stirring Still, 127.

61. Three Novels, 304.

62. Thompson, Waking, Dreaming, Being, 52.

63. Thompson, Waking, Dreaming, Being, xxxiii.

64. Thompson, Waking, Dreaming, Being, 53.

65. Miri Albahari, Analytical Buddhism: The Two-Tiered Illusion of Self (New York: Springer, 2006), 66.

66. The Unnamable, 286-87.

67. Thompson, Waking, Dreaming, Being, 121.

68. Texts for Nothing, 3 .

69. Three Novels, 180.

70. Three Novels, 199.

71. All That Fall and Other Plays for Radio and Screen, ed. by Everett Frost (London: Faber, 2009), 98.

72. Three Novels, 228.

73. Texts for Nothing, 4.

74. Three Novels, 317.

75. The Letters of Samuel Beckett: Volume 2: 1941-1956, ed. by Fehsenfeld et al. (Cambridge: Cambridge University Press, 2011), 130.

\section{Selected Bibliography}

Albahari, Miri. 2006. Analytical Buddhism: The Two-Tiered Illusion of Self. New York: Springer.

Barry, Elizabeth, ed. 2018. Special Issue on 'Beckett, Language and the Mind'. Journal of Beckett Studies 17: 1-2.

Flanagan, Owen. 2011. The Bodhisattva's Brain: Buddhism Naturalized. Cambridge, MA: MIT Press.

Herman, David, ed. 2011. The Emergence of Mind: Representations of Consciousness in Narrative Discourse in English. Lincoln: University of Nebraska Press.

Kearns, Michael S. 1987. Metaphors of Mind in Fiction and Psychology. Lexington: University Press of Kentucky.

Lindahl, Jared R. et al. 2014. A Phenomenology of Meditation-Induced Light Experiences: Traditional Buddhist and Neurobiological Perspectives. Frontiers in Psychology 4: 973.

Maude, Ulrika, and Matthew Feldman, eds 2009. Beckett and Phenomenology. London: Continuum. 
Maude, Ulrika. 2009. Beckett, Technology and the Body. New York: Cambridge University Press.

Sotirova, Violeta. 2013. Consciousness in Modernist Fiction: A Stylistic Study. Basingstoke: Palgrave Macmillan.

Thompson, Evan. 2015. Waking, Dreaming, Being: Self and Consciousness in Neuroscience, Meditation, and Philosophy. New York: Columbia University Press.

Open Access This chapter is licensed under the terms of the Creative Commons Attribution 4.0 International License (http://creativecommons.org/licenses/ by $/ 4.0 /$ ), which permits use, sharing, adaptation, distribution and reproduction in any medium or format, as long as you give appropriate credit to the original author(s) and the source, provide a link to the Creative Commons license and indicate if changes were made.

The images or other third party material in this chapter are included in the chapter's Creative Commons license, unless indicated otherwise in a credit line to the material. If material is not included in the chapter's Creative Commons license and your intended use is not permitted by statutory regulation or exceeds the permitted use, you will need to obtain permission directly from the copyright holder.

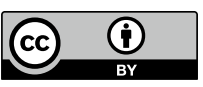

